\title{
EFFECTS OF AGING ON THE PLANTAR SOFT TISSUE PROPERTIES UNDER THE METATARSAL HEADS AT DIFFERENT IMPACT VELOCITIES
}

\author{
Chim-Chin Hsu,* Wen-Chung Tsai,* Carl Pai-Chu Chen,* Yio-Wha Shau, ${ }^{\dagger}$ \\ Chung-Li Wang, ${ }^{\ddagger}$ Max Jin-Lung Chen, $*$ and KIng-Jen $\mathrm{CHANG}^{\S}$ \\ *Department of Physical Medicine and Rehabilitation, Chang Gung Memorial Hospital, Taipei, Taiwan; ${ }^{\dagger}$ Institute of \\ Applied Mechanics, ${ }^{\star}$ Departments of Orthopedic Surgery and ${ }^{\S}$ General Surgery, Angiogenesis Research Center, \\ National Taiwan University, Taipei, Taiwan
}

(Received 19 October 2004, revised 16 May 2005, in final form 26 May 2005)

\begin{abstract}
The plantar soft tissue properties under the metatarsal heads at different impact velocities in different age groups were measured. Each metatarsus of the left foot in healthy young adults $(n=9,19$ to 35 years old) and in healthy older persons $(n=10,42$ to 72 years old) was examined in vivo using a self-constructed loading-unloading device at low, medium and high impact status; the impact velocities of the device were about $2.5,5$ and $10 \mathrm{~cm} / \mathrm{s}$, respectively. The device comprised a 5- to 12-MHz linear-array ultrasound transducer, a miniature load cell and a fixation frame. From low to high impact status, the elastic modulus $(E)$ in young adults significantly increased from about $300 \mathrm{kPa}$ to about $500 \mathrm{kPa}$. However, the $E$ in the older group did not show this trend. From low to high impact status, the energy dissipation ratio $(E D R)$ of the metatarsus significantly increased from about $30 \%$ to about $60 \%$ in the young group and significantly increased from about $40 \%$ to about $\mathbf{7 0 \%}$ in the older group. Most of the metatarsus in the older subjects had significantly greater $E$ and $E D R$ than those in the younger persons. (E-mail: chungli@ha.mc.ntu.edu.tw) @ 2005 World Federation for Ultrasound in Medicine \& Biology.
\end{abstract}

Key Words: Metatarsus, Biomechanics, Aging, Ultrasonography, Impact velocity.

\section{INTRODUCTION}

In an active and healthy society, foot problems are becoming more prevalent in the aging population (Whitney 2003). Metatarsalgia, a well-recognized but loosely defined pathologic entity, is caused by excessive sports activities (Quirk 1996) and is frequently associated with the aging process (Edelstein 1988). Abnormal foot biomechanics caused by tissue changes under the metatarsal heads has been proposed to be a key risk factor for this lesion (Whitney 2003). Therefore, it is important to identify the plantar soft tissue properties under the metatarsal heads, because they can provide basic information about the material itself or indicate the presence of a disease (Brink 1995).

Features of viscoelasticity, including creep, stress relaxation and hysteresis can be seen in all biologic tissues (Fung 1993). The plantar soft tissues under the

Address correspondence to: Dr. Chung-Li Wang, M.D., Ph.D., Prof., Department of Orthopedic Surgery, National Taiwan University Hospital, No. 7, Chungshan South Rd., Taipei 100 Taiwan. E-mail: chungli@ha.mc.ntu.edu.tw metatarsal heads, comprising a complex framework of the connective tissue and closely packed fat cells, are optimized for load-bearing during ambulation (BojsenMøller and Flagstad 1976). Healthy persons may voluntarily modify their walking velocity and the plantar soft tissues have to tolerate the ground reaction force at different impact velocities. It would be interesting to examine the plantar soft tissue behaviors at different impact velocities.

The plantar soft tissue thickness under each metatarsal head has been evaluated ultrasonographically (Gooding et al. 1986; Cavanagh 1999; Zheng et al. 2000) and roentgenographically (Dreeben et al. 1987). The elastic modulus of the metatarsus and of the soft tissues between the metatarsal heads is measured either by an ultrasonic indentation probe (Zheng et al. 2000) or by the method of integrating the contact pressure measurement technique into a magnetic resonance imaging system (Gefen et al. 2001), respectively. Klaesner et al. (2002) developed a 3-D indentor system to measure the tissue stiffness of the metatarsus; others used a durometer (Brink 1995). The hysteresis of the plantar soft tissue 
under each metatarsus in healthy young subjects has been measured by an ultrasound (US)-based loadingunloading device (Wang et al. 1999). However, how the soft tissue properties under the metatarsal heads react to different impact velocities has not been investigated.

Ultrasonography can provide dynamic information on the soft tissue structures in their physiological range of motion and is ideal for continuous monitoring of the plantar soft tissue thickness during a loading-unloading cycle. The present study developed an US-load-cell system to investigate the effects of aging on the plantar soft tissue properties under metatarsal heads at different impact velocities in vivo.

\section{MATERIALS AND METHODS}

A total of 19 healthy volunteers were recruited and were further divided into the young and the older groups. There were 4 women and 5 men in the younger group and 5 women and 5 men in the older group. The mean age and body mass index (BMI) were $24.0 \pm 1.8$ years (range: 19 to 35 years) and $23.0 \pm 1.4 \mathrm{~kg} / \mathrm{m}^{2}$, respectively, in the young group. The mean age and BMI were $54.6 \pm 3.3$ years (range: 42 to 72 years) and $26.0 \pm 1.5$ $\mathrm{kg} / \mathrm{m}^{2}$, respectively, in the older group. These subjects did not have any foot problems within the recent 6 months. The above and subsequently presented data were all mean \pm standard error of mean.

A 5- to $12-\mathrm{MHz}$ linear-array US transducer (HDI5000, Advanced Technology Laboratory, Bothell, WA, USA) with the area of $4.73 \mathrm{~cm}^{2}$ was incorporated into an indenter that was equipped with a miniature load cell (LM-10KA, Kyowa Electronic Instruments Corp., Kyowa, Japan). They were then mounted on a device comprising a plastic fixation cover, stainless steel frame and a guiding linear bearing (Fig. 1). The hand-held indenter moved the transducer to and fro, to load and unload the metatarsus. Each subject was placed in the supine position with the ankle in neutral and the knee in straight positions. All of the subjects were examined by an experienced operator.

The skin was pretreated with alcohol, to facilitate US penetration into the plantar soft tissues. Then, the transducer was put along each toe ray and contacted the ball of the foot via a water bag. With the US transducer slightly detached from the skin and with the US couplant filled in between, the unloaded plantar soft tissue thickness under the metatarsal head (UPTM) was measured from the skin surface to the nearest metatarsal head cortex on the sonogram. Thereafter, the probe loaded the metatarsus rhythmically with low, medium and high impact status, according to the frequency of a metronome (quartz metronome SQ-77, Seiko S-Yard Co. Ltd., Tokyo, Japan) at $0.5 \mathrm{~Hz}, 1 \mathrm{~Hz}$ and $2 \mathrm{~Hz}$, respectively. A beep sound was generated as soon as the compression

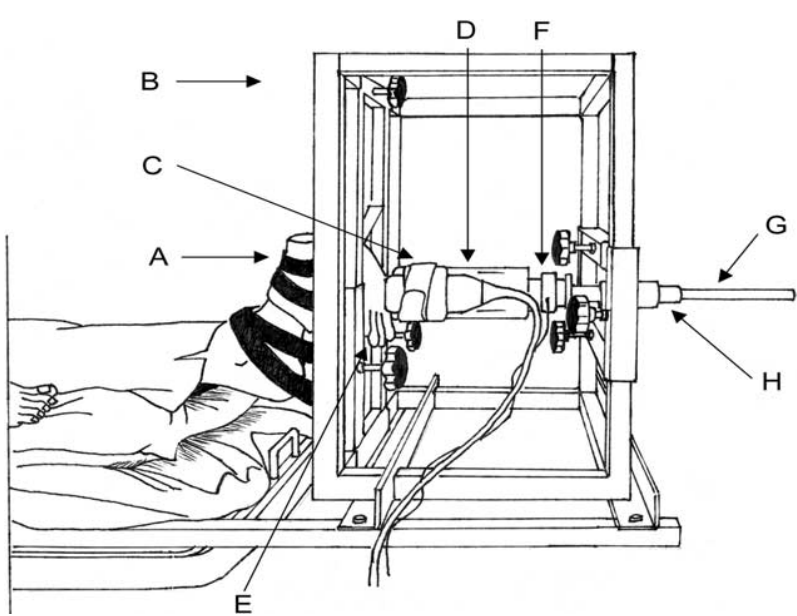

Fig. 1. Experimental design of this study. The tested left foot was placed in a plastic rim (A) of a stainless-steel frame (B) that allowed repeated loading-unloading examination. US transducer $(C)$ contacted with the examined region through a water bag (E). The transducer was further connected with a load cell (F) via an adapter (D). A hand-held steel rod (G) could move the transducer freely in a bearing $(\mathrm{H})$ at different maximum impact velocities. M-mode morphologies and piezoelectric signals were transmitted to the high-resolution US system and an IBM-compatible personal computer, respectively.

force reached $98 \mathrm{~N}$ and then the applied force was relieved immediately. The averaged pressure, calculated from the total force divided by the area of the US transducer, was used to analyze the stress-strain relationship in the study. With a contact area of $4.73 \mathrm{~cm}^{2}$, the maximum stress on the tested metatarsus applied by the US transducer was equivalent to $207 \mathrm{kPa}$. The water bag was open to the atmosphere. The tested metatarsus was about $5 \mathrm{~cm}$ below the water level and the water level in the bag was raised slightly (typically less than $0.5 \mathrm{~cm}$ ) during the loading process. The pressure acting on the tested metatarsus by the water bag was about 500 to 550 $\mathrm{Pa}$, which was about $0.25 \%$ of the maximum loading pressure applied by the US transducer. Therefore, it is considered that the pressure on the tested metatarsus applied by the water bag could be neglected during the examination.

The impact velocity was defined as the rate of deformation of the water bag at the instant that the transducer contacted the skin. After the transducer touched the metatarsus, the plantar soft tissue started to deform in responding to the loading force of the transducer. The average loading rate was calculated by using the maximum deformation of the plantar soft tissue divided by the loading time interval (Wang et al. 1999). Moreover, the average force/time slope was given by the maximum compression force divided by the loading time interval (Klaesner et al. 2002).

The mean impact velocity corresponding to low, medium and high impacts of the young subjects was 
$2.36 \pm 0.09 \mathrm{~cm} / \mathrm{s}$ (range: 1.46 to $3.62 \mathrm{~cm} / \mathrm{s}$ ), $5.47 \pm$ $0.14 \mathrm{~cm} / \mathrm{s}$ (range: 4.02 to $6.64 \mathrm{~cm} / \mathrm{s}$ ) and $10.5 \pm 0.3 \mathrm{~cm} / \mathrm{s}$ (range: 6.76 to $12.6 \mathrm{~cm} / \mathrm{s}$ ), respectively. The mean impact velocity corresponding to low, medium and high impacts of the older subjects was $2.42 \pm 0.10 \mathrm{~cm} / \mathrm{s}$ (range: 1.34 to $3.8 \mathrm{~cm} / \mathrm{s}$ ), $5.26 \pm 0.13 \mathrm{~cm} / \mathrm{s}$ (range: 3.27 to $6.71 \mathrm{~cm} / \mathrm{s}$ ) and $9.92 \pm 0.22 \mathrm{~cm} / \mathrm{s}$ (range: 7.06 to 13.1 $\mathrm{cm} / \mathrm{s}$ ), respectively. The average loading rate corresponding to low, medium and high impacts of the young subjects was $1.09 \pm 0.05 \mathrm{~cm} / \mathrm{s}$ (range: 0.71 to $1.68 \mathrm{~cm} / \mathrm{s}$ ), $1.87 \pm 0.05 \mathrm{~cm} / \mathrm{s}$ (range: 1.26 to $2.45 \mathrm{~cm} / \mathrm{s}$ ) and $2.88 \pm$ $0.08 \mathrm{~cm} / \mathrm{s}$ (range: 2.12 to $3.74 \mathrm{~cm} / \mathrm{s}$ ), respectively. The average loading rate corresponding to the low, medium and high impacts of the older subjects was $0.98 \pm 0.04$ $\mathrm{cm} / \mathrm{s}$ (range: 0.47 to $1.42 \mathrm{~cm} / \mathrm{s}$ ), $1.75 \pm 0.06 \mathrm{~cm} / \mathrm{s}$ (range: 1.21 to $2.58 \mathrm{~cm} / \mathrm{s}$ ) and $2.89 \pm 0.12 \mathrm{~cm} / \mathrm{s}$ (range: 2.03 to $4.78 \mathrm{~cm} / \mathrm{s}$ ), respectively. The force/time slope at the low, medium and high impacts of the young subjects was 227 $\pm 13 \mathrm{~N} / \mathrm{s}$ (range: 118 to $490 \mathrm{~N} / \mathrm{s}$ ), $357 \pm 12 \mathrm{~N} / \mathrm{s}$ (range: 265 to $490 \mathrm{~N} / \mathrm{s}$ ) and $566 \pm 21 \mathrm{~N} / \mathrm{s}$ (range: 392 to 817 $\mathrm{N} / \mathrm{s}$ ), respectively. The force/time slope at the low, medium and high impacts of the older subjects was $206 \pm$ $9.6 \mathrm{~N} / \mathrm{s}$ (range: 111 to $338 \mathrm{~N} / \mathrm{s}$ ), $351 \pm 15 \mathrm{~N} / \mathrm{s}$ (range: 181 to $649 \mathrm{~N} / \mathrm{s}$ ) and $550 \pm 20 \mathrm{~N} / \mathrm{s}$ (range: 329 to 817 $\mathrm{N} / \mathrm{s}$ ), respectively.

Each metatarsus of the left foot in every subject was monitored continuously during loading-unloading tests by motion-mode (M-mode) at a sampling rate of $100 \mathrm{~Hz}$ (Fig. 2). We examined the metatarsus with a slower impact velocity first and then increased the velocity sequentially. Each metatarsus had a 10-min interval freeof-loading between each measurement (Fung 1993). The load cell signals were magnified by an amplifier (INA128/UAF42, Texas Instruments, Austin, TX, USA), in which frequency above $10 \mathrm{~Hz}$ was filtered. The signals were digitized by an analog-to-digital converter card (PCI-9118 DG, AD Link Technology Inc., Taipei, Taiwan) and were then transmitted to an IBM-compatible personal computer. A pulse generator was used to synchronize the load cell and the tissue thickness information. By carefully calibrating the system with an impulsive motion, the time lag between the load cell signals and the ultrasonic M-mode was found to be about $20 \mathrm{~ms}$ (Shau et al. 1999).

The elastic modulus $(E)$ of the plantar soft tissue under the metatarsal head was defined as:

$$
E=\frac{P_{\max }}{\left(\frac{U P T M-P T M_{\max }}{U P T M}\right)},
$$

where $P_{\max }$ and $P T M_{\max }$ represented the maximum stress and plantar soft tissue thickness measured at maximum stress, respectively. The denominator of the above formula represented the maximum strain.
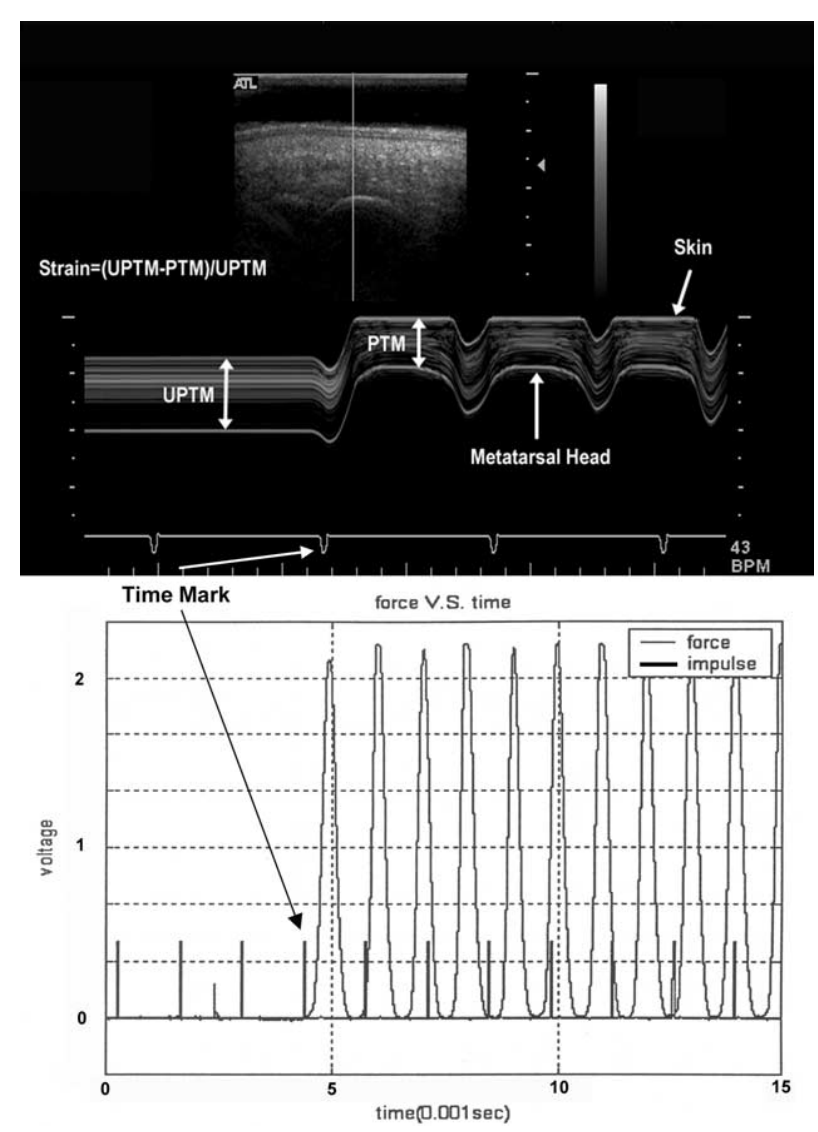

Fig. 2. B- and M-mode images of the plantar soft tissue under left third metatarsus (top) in a 57-year-old healthy man. The vertical line of the upper panel represented the US scanning line of the M-mode (bottom). The two sinusoid lines in the lower panel are the skin and cortex of the metatarsal head at different times in loading-unloading cycles. UPTM was measured from the skin to the nearest cortex. Plantar soft tissue thickness under the metatarsal head (PTM) during a loadingunloading cycle could be easily measured from M-mode. Time marks produced by a pulse generator were used to synchronize load cell signals (lower panel) in the IBM-compatible personal computer and the US image.

In terms of stress-strain relationship, the metatarsus showed a nonlinear looping curve (Fig. 3). The upper loading curve and the lower unloading curve formed a closed area that represented the dissipated energy. Thus, the energy dissipation ratio $(E D R)$, indicating the shock absorbency of plantar soft tissues under the metatarsal heads, was given as:

$E D R=($ bounded area/area under the loading curve $)$

$$
\times 100 \%
$$

The area was estimated by the numerical integration-based trapezoid rule using Microsoft Excel (Microsoft Corp., Redmond, WA, USA).

Reliability was determined by a test-retest procedure. We repeated the measurement with the three dif- 


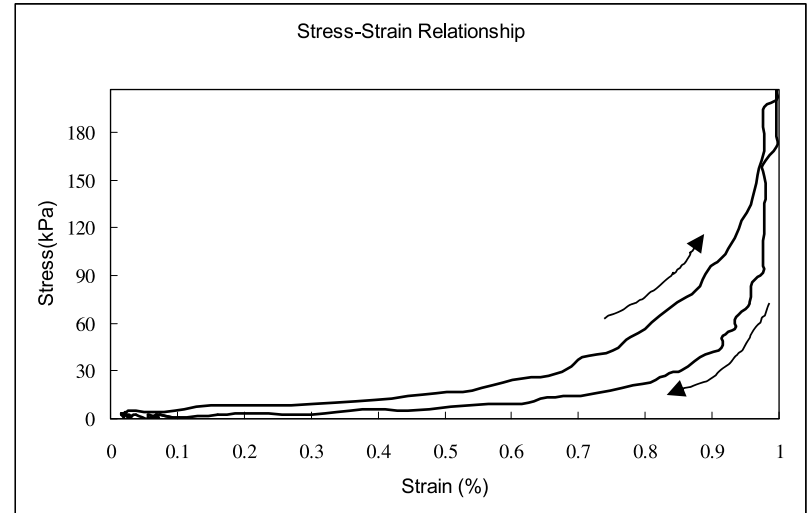

Fig. 3. An example of the stress-strain curve of plantar soft tissue under the fourth metatarsus in a 20 -year-old healthy woman. The $\mathrm{x}$-axis and $\mathrm{y}$-axis represented the strain and stress, respectively. The upper loading curve $(\nearrow)$ and the lower unloading curve $(\swarrow)$ formed a closed area. EDR is defined as the ratio of this closed area to the area formed by the loading curve, the vertical line and the $\mathrm{x}$-axis.

ferent impact statuses on the plantar soft tissue under the second metatarsal head of the left foot in five healthy individuals at intervals of $10 \mathrm{~min}, 2 \mathrm{~h}$ and 1 week after the first measurement. The coefficient of variation $(\mathrm{CV})$ was then calculated from the 20 measurements at each impact status and ranged from 1 to $3 \%$ for the UPTM and $E$. The $\mathrm{CV}$ for the EDR ranged from $2.56 \%$ to $8.45 \%$. MannWhitney $U$ test was used to compare the age, BMI, $U P T M, E, E D R$, maximum strain, impact velocities, loading rates and force/time slopes between the two groups. The relationship between the BMI, UPTM and the mechanical properties was analyzed by the Pearson correlation. Repeated measurements were conducted to compare differences of $E$ and $E D R$ of the plantar soft tissues under the metatarsal heads among different impact statuses. Fisher's exact test was used to evaluate the gender distribution between the two groups. A $p$ value of less than 0.05 was regarded as statistically significant.

\section{RESULTS}

Gender distribution and BMI were not significantly different between the two groups. Significant difference $(p<0.001)$ of the age distribution was observed between the two groups. The mean UPTM had a decrease trend from the first to the fifth metatarsus in both groups, with values of $1.36 \pm 0.05,1.23 \pm 0.06,1.13 \pm 0.05,1.09 \pm$ 0.06 and $0.89 \pm 0.03 \mathrm{~cm}$ in the younger group and $1.40 \pm$ $0.05,1.31 \pm 0.06,1.21 \pm 0.05,1.16 \pm 0.03$ and $1.07 \pm$ $0.06 \mathrm{~cm}$ in the older group. There was no significant difference of the thickness between the two groups. The impact velocities, loading rates and force/time slopes were not significantly different between the two groups, either.
The $E$ in most of the metatarsus in the young persons had a significant increase trend from low to high impact status. However, the $E$ of the metatarsus in the older individuals measured at different impact statuses did not share the same tendency (Fig. 4). The second to fifth metatarsus in the older persons were stiffer than those in the younger persons at low and medium impact status. The first metatarsus in the older subjects had greater tissue stiffness than that in the younger subjects at the three different impact conditions (Table 1).

The maximum strain in the young subjects had a significant decrease trend from low to high impact status. The maximum strain in the older subjects measured at different impact status did not show the same trend. Almost all the plantar soft tissues under the metatarsal heads in the older persons deformed less than those in the young subjects at the three impact statuses (Table 2).

The EDR in almost all the metatarsus increased significantly from low to high impact status (Fig. 5). Under the same impact status, the older subjects had significantly greater EDRs than the young subjects in a majority of the metatarsus. At the low impact status, there was no significant difference of the EDR in the second to fourth metatarsus between the two groups. The $E D R$ of the fifth metatarsus measured at the high impact status was not significantly different between the two groups. The detail information is listed in Table 3.

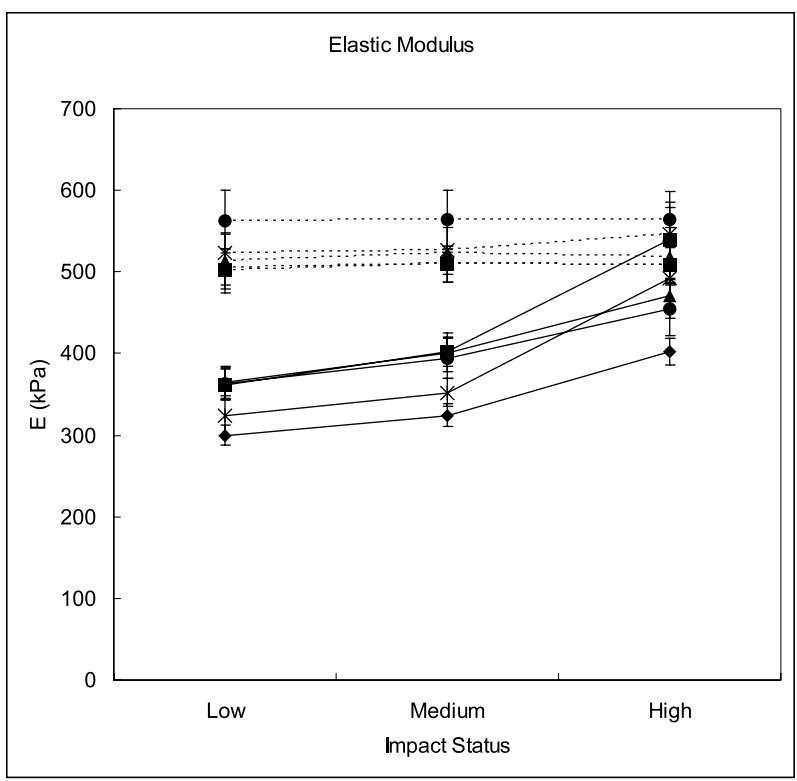

Fig. 4. $E$ of the young and older groups at different impact status. The $E$ of the five metatarsals $(\bullet=$ the first metatarsus; $\mathbf{\square}=$ the second metatarsus; $\boldsymbol{\Delta}=$ the third metatarsus; $\bullet=$ the fourth metatarsus; $X=$ the fifth metatarsus) in the young subjects (-) increased with increasing impact velocity. However, stiffness of the older group $(\cdots)$ lost the rate sensitivity. The metatarsus in the older group had greater tissue stiffness than those in the young group, except at high-impact status. Data are presented as mean \pm one standard error of the mean. 
Table 1. Elastic modulus of the plantar soft tissues under the metatarsal heads at different impact status in the two groups

\begin{tabular}{llccc}
\hline & Impact status & Young & Older & $p$ value* \\
\hline \multirow{2}{*}{ MT1 (kPa) } & Low & $300 \pm 12$ & $509 \pm 21$ & 0.003 \\
& Medium & $324 \pm 14$ & $505 \pm 20$ & 0.003 \\
& High & $402 \pm 16$ & $511 \pm 32$ & 0.042 \\
& $p$ value & 0.021 & 0.992 & - \\
MT2 $(\mathrm{kPa})$ & Low & $362 \pm 19$ & $500 \pm 26$ & 0.001 \\
& Medium & $402 \pm 18$ & $502 \pm 28$ & 0.021 \\
& High & $539 \pm 46$ & $494 \pm 22$ & 0.720 \\
& $p$ value & 0.003 & 0.803 & - \\
MT3 $(\mathrm{kPa})$ & Low & $365 \pm 20$ & $517 \pm 34$ & 0.003 \\
& Medium & $401 \pm 24$ & $527 \pm 37$ & 0.012 \\
& High & $471 \pm 19$ & $547 \pm 32$ & 0.063 \\
& $p$ value & 0.010 & 0.462 & - \\
MT4 (kPa) & Low & $363 \pm 20$ & $564 \pm 35$ & $<0.001$ \\
& Medium & $394 \pm 24$ & $568 \pm 36$ & 0.001 \\
& High & $455 \pm 33$ & $545 \pm 37$ & 0.114 \\
& $p$ value & 0.032 & 0.826 & - \\
MT5 (kPa) & Low & $324 \pm 24$ & $528 \pm 29$ & 0.004 \\
& Medium & $352 \pm 17$ & $530 \pm 33$ & 0.006 \\
& High & $492 \pm 48$ & $557 \pm 31$ & 0.376 \\
& $p$ value & 0.536 & 0.694 & - \\
\hline
\end{tabular}

Data are presented as mean \pm standard error of mean. MT1-5 $=$ the plantar soft tissue under the first to the fifth metatarsus. * Mann-Whitney U-test for estimation of differences between the two groups; ${ }^{\dagger}$ repeated measurement test for estimation of differences within subjects.

The UPTM of the fourth metatarsus $(\mathrm{r}=0.584, p=$ $0.018)$ and its $E D R$ measured at the medium impact status $(\mathrm{r}=0.578, p=0.03)$ had fair correlation with the BMI. The $E$ of all the metatarsals did not correlate with

Table 2. The maximum strain of the plantar soft tissues under the metatarsal heads at different impact status in the two groups

\begin{tabular}{llccc}
\hline & Impact status & Young & Older & $p$ value* \\
\hline \multirow{2}{*}{ MT1 (\%) } & Low & $69.2 \pm 2.6$ & $41.4 \pm 1.6$ & 0.003 \\
& Medium & $64.2 \pm 2.8$ & $41.1 \pm 1.6$ & 0.003 \\
& High & $51.8 \pm 2.0$ & $41.2 \pm 1.8$ & 0.008 \\
& $p$ value ${ }^{\dagger}$ & 0.006 & 0.829 & - \\
MT2 (\%) & Low & $58.4 \pm 3.1$ & $47.7 \pm 6.9$ & 0.011 \\
& Medium & $52.2 \pm 2.3$ & $42.6 \pm 2.4$ & 0.021 \\
& High & $40.8 \pm 3.5$ & $42.1 \pm 2.4$ & 0.661 \\
& $p$ value & $<0.001$ & 0.287 & - \\
MT3 (\%) & Low & $58.0 \pm 3.0$ & $41.7 \pm 2.4$ & 0.003 \\
& Medium & $53.0 \pm 3.3$ & $40.9 \pm 2.4$ & 0.012 \\
& High & $44.4 \pm 1.6$ & $41.4 \pm 2.6$ & 0.549 \\
& $p$ value & 0.001 & 0.308 & - \\
MT4 (\%) & Low & $58.1 \pm 3.0$ & $38.0 \pm 2.2$ & $<0.001$ \\
& Medium & $53.7 \pm 3.4$ & $37.7 \pm 2.0$ & 0.001 \\
& High & $47.2 \pm 3.5$ & $37.7 \pm 2.0$ & 0.036 \\
& $p$ value & $<0.001$ & 0.803 & - \\
MT5 (\%) & Low & $65.0 \pm 4.5$ & $40.0 \pm 1.8$ & 0.004 \\
& Medium & $59.2 \pm 2.8$ & $40.1 \pm 2.0$ & 0.004 \\
& High & $43.0 \pm 4.6$ & $38.8 \pm 2.2$ & 0.497 \\
& $p$ value ${ }^{\dagger}$ & 0.114 & 0.593 & - \\
\hline
\end{tabular}

Data are presented as mean \pm standard error of mean. MT1-5 the plantar soft tissue under the first to the fifth metatarsus. * MannWhitney $U$-test for estimation of differences between groups; ${ }^{\dagger}$ repeated measurement test for estimation of differences within subject.

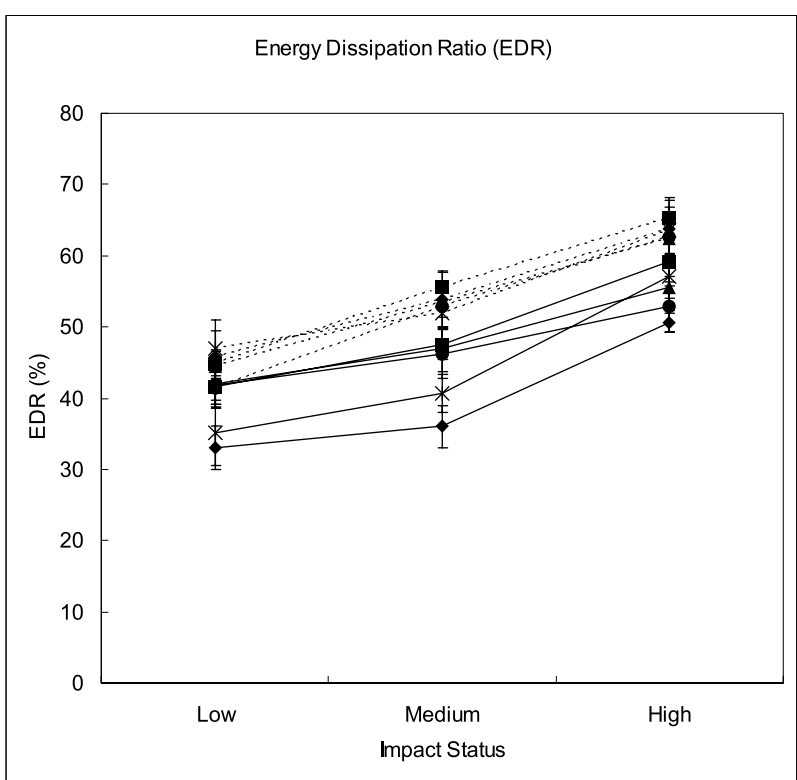

Fig. 5. EDR of the young and older groups at different impact status. The EDRs of the five metatarsals $(=$ the first metatarsus; $\mathbf{\square}=$ the second metatarsus; $\boldsymbol{\Delta}=$ the third metatarsus; - = the fourth metatarsus; $\times=$ the fifth metatarsus) in the young subjects $(-)$ and the older subjects $(\cdots)$ increased with increasing impact velocity. The older group had greater EDRs than those in the young group. Data are presented as mean \pm one standard error of mean.

the BMI. Fair correlation could be seen between the $U P T M$ of the second metatarsus and its $E$ measured at low impact status $(\mathrm{r}=0.527, p=0.002)$. Fair correlation was also observed between the UPTM of the third metatarsus and its $E D R$ measured at low impact status (r $=0.456, p=0.05$ ).

\section{DISCUSSION}

Cavanagh (1999) has used ultrasonography to study the deformation of the soft tissue underneath the second metatarsal head during walking in five healthy subjects with the average age of 36.6 years. The maximum strain measured at the maximum force of around $160 \mathrm{~N}$ was $45.7 \%$. In-shoe peak plantar pressure at the metatarsal heads of young persons, evaluated at a walking speed of $1.66 \mathrm{~m} / \mathrm{s}$ with capacitance-based pressure-measuring insoles, ranged from $185 \mathrm{kPa}$ to $198 \mathrm{kPa}$ (Rozema et al. 1996). In this study, the maximum strain of the second metatarsus in the young group was $58.4 \pm 3.1 \%, 52.2 \pm$ $2.3 \%$ and $40.8 \pm 3.5 \%$ at low, medium and high impact status, respectively. The maximum tissue deformation was close to that in the previous report. The maximum stress on each metatarsus was $207 \mathrm{kPa}$ in each test, which was similar to the above in-shoe peak plantar walking pressure. Thus, the experimental design in the study can simulate the physiological walking condition. 
Table 3. Energy dissipation ratio of the plantar soft tissues under the metatarsal heads at different impact status in the two groups

\begin{tabular}{|c|c|c|c|c|}
\hline & Impact status & Young & Older & $p$ value ${ }^{*}$ \\
\hline \multirow[t]{4}{*}{ MT1 (\%) } & Low & $33.0 \pm 3.0$ & $51.6 \pm 3.4$ & 0.020 \\
\hline & Medium & $36.0 \pm 2.9$ & $61.8 \pm 2.5$ & 0.003 \\
\hline & High & $50.6 \pm 1.3$ & $70.4 \pm 4.3$ & 0.004 \\
\hline & $p$ value $^{\dagger}$ & 0.018 & 0.003 & - \\
\hline \multirow[t]{4}{*}{ MT2 (\%) } & Low & $41.6 \pm 3.1$ & $48.1 \pm 2.4$ & 0.113 \\
\hline & Medium & $47.6 \pm 2.2$ & $61.8 \pm 2.7$ & 0.001 \\
\hline & High & $59.2 \pm 3.5$ & $70.7 \pm 3.5$ & 0.043 \\
\hline & $p$ value $^{\dagger}$ & 0.001 & $<0.001$ & - \\
\hline \multirow[t]{4}{*}{ MT3 (\%) } & Low & $42.1 \pm 3.0$ & $46.6 \pm 2.7$ & 0.447 \\
\hline & Medium & $46.9 \pm 3.2$ & $58.8 \pm 1.8$ & 0.016 \\
\hline & High & $55.6 \pm 1.5$ & $68.6 \pm 2.4$ & $<0.001$ \\
\hline & $p$ value $^{\dagger}$ & 0.015 & $<0.001$ & - \\
\hline \multirow[t]{4}{*}{ MT4 (\%) } & Low & $41.8 \pm 3.0$ & $41.7 \pm 3.7$ & 0.743 \\
\hline & Medium & $46.2 \pm 3.4$ & $57.9 \pm 3.5$ & 0.055 \\
\hline & High & $52.8 \pm 3.5$ & $71.4 \pm 2.0$ & $<0.001$ \\
\hline & $p$ value $^{\dagger}$ & 0.022 & $<0.001$ & - \\
\hline \multirow[t]{4}{*}{ MT5 (\%) } & Low & $35.1 \pm 4.6$ & $52.9 \pm 3.6$ & 0.016 \\
\hline & Medium & $40.6 \pm 2.7$ & $57.7 \pm 3.9$ & 0.048 \\
\hline & High & $57.0 \pm 4.7$ & $67.9 \pm 3.8$ & 0.194 \\
\hline & $p$ value $^{\dagger}$ & 0.491 & 0.014 & - \\
\hline
\end{tabular}

Data are presented as mean \pm standard error of mean. MT1-5 $=$ the plantar soft tissue under the first to the fifth metatarsus. * MannWhitney $U$-test for estimation of differences between groups; ${ }^{\dagger}$ repeated measurement test for estimation of differences within subject.

In agreement with the previous reports concerning the UPTM in the young persons (Wang et al. 1999) and the effects of aging on the heel-pad stiffness (Hsu et al. 1998), the UPTM decreased progressively from the first to the fifth metatarsus in both groups and the plantar soft tissues in the older persons stiffened. Although the UPTM and the BMI were not significantly different between the two groups, yet there is a trend for a thicker UPTM and a greater BMI in the older subjects. An increase of body fat distribution in the plantar soft tissues may cause the increase of the UPTM in the older persons. The increased fatty content in the sole of the foot may lead to increased pressure in the sealed fibrous compartment and, finally, result in the harder plantar soft tissues in the older persons (Prichasuk et al. 1994).

A simple linear elasticity model (Fung 1993) describes the elastic modulus of a material as:

$$
\sigma(t)=E \varepsilon(t)
$$

Both the stress, $\sigma(t)$, and strain, $\epsilon(t)$, are functions of time. Typically, as the stress rate increases, the strain for the soft tissue decreases. This results in an increase of the elastic modulus $E$ with the increase of the stress rate. It has been reported that the elastic modulus in the metatarsus of healthy persons about 22-years-old measured with an US indentation system ranged from 40 to $50 \mathrm{kPa}$ at a loading rate of 0.1 to $0.2 \mathrm{~cm} / \mathrm{s}$ (Zheng et al. 2000). In that study, the stiffness increased significantly from about $300 \mathrm{kPa}$ to $500 \mathrm{kPa}$ in the young adults as the loading rate increased from $1 \mathrm{~cm} / \mathrm{s}$ to $3 \mathrm{~cm} / \mathrm{s}$. It is obvious that the young metatarsus stiffens as the loading rate increases, indicating its rate-dependency.

Klaesner et al. (2002) measured the tissue stiffness of the metatarsus in healthy persons about 56 years old and the elastic modulus ranged from 81 to $228 \mathrm{kPa}$. Their force/time slopes ranged from 20 to $30 \mathrm{~N} / \mathrm{s}$, using a device that consisted of a load cell mounted on a cylindrical stylus. In the present study, the plantar soft tissue stiffness measured at higher force/time slopes (range: $111 \mathrm{~N} / \mathrm{s}$ to $817 \mathrm{~N} / \mathrm{s}$ ) ranged from 500 to $568 \mathrm{kPa}$, which was greater than those in the above report. It is noted that the $E$ increased as the force/time slope increased from 20 $\mathrm{N} / \mathrm{s}$ to $111 \mathrm{~N} / \mathrm{s}$. Nevertheless, the plantar soft tissue stiffness did not increase with further increase in force/ time slope in the older persons.

Findings concerning the dissipated energy in the human heel pad, measured from $0.06 \mathrm{~cm} / \mathrm{s}$ to $1.0 \mathrm{~m} / \mathrm{s}$, ranged from $23.7 \%$ to $95 \%$ (Bennett and Ker 1990; Hsu et al. 1998; Kinoshita et al. 1996). Wang et al. (1999) had measured the $E D R$ of the metatarsus in healthy subjects about 30 years old at the loading rate of $0.06 \mathrm{~cm} / \mathrm{s}$ and the value was about $30 \%$. The EDR in plantar soft tissues under the metatarsal heads also increased as the impact velocity increased in all our subjects, indicating its ratedependent characteristics. The plantar soft tissue deforms less in high-impact velocity, resulting in a steeper loading curve, and finally leads to the increased $E D R$ in higher-impact velocity. Unlike the elastic modulus, simply determined from the beginning and the end-loaded condition, the EDR records the loading-unloading process and can reflect the nonlinear tissue properties. This advantage may describe effects of aging on the metatarsus more clearly than the tissue stiffness.

Under the same impact status, all the metatarsals in the older group had greater EDRs than those in the younger group. This observation was similar to that in the senescent heel pad (Hsu et al. 1998). The aging metatarsus becomes stiffened at each instantaneous point during the loading process. Slow tissue recovery may also occur during the unloading process of the aging metatarsus. The increase of $E D R$ in the older persons may be caused by a steeper loading curve and a poor rebound unloading curve. It has been reported that a decrease of the water component plays a role in senescent foot tissue properties (Kuhns 1949). A gradual change of collagen and a decrease in the elastic fibers may also contribute to the aging of tissues (Haut and Haut 1997).

The $E$ and $E D R$ in most of the metatarsals did not correlate with the BMI in the study. The findings were similar to those in the study for the measurement of the heel-pad mechanical properties in elderly subjects and diabetic patients (Hsu et al. 2000) but were contrary to those in the study for plantar soft tissues properties in 
young persons (Wang et al. 1999). More investigation for the plantar soft tissue mechanical properties may be necessary to reach a conclusion about the relationship between the plantar soft tissue biomechanics and the BMI. The $E$ and $E D R$ had been normalized with the initial thickness and, therefore, no correlation between them and the UPTM could be expected.

In this study, we used the averaged pressure, calculated from the total force divided by the contact area of the US transducer, to analyze the stress-strain relationship of the metatarsus. The pressure distribution may be different from site to site and may be changed during the compression process, because of the underlying bones. The calculated $E$ may be affected by the boundary conditions and further study is warranted.

The present study demonstrates that individuals in different age groups may have different plantar soft tissue responses to varied impact velocities. The tissue properties are also different between the different age groups. Effects of aging on plantar soft tissues under metatarsal heads are stiffened soft tissue, loss of tissue response to different impact velocities and high dissipated energy. These changes may impair the tissue reaction to a sudden or repetitive stress and eventually lead to the development of metatarsalgia in the aging people. Therefore, adequate footwear is suggested for aging persons. Because US is widely available, the facility in this study can be easily built to measure the plantar soft tissue properties. This noninvasive technique can be an adjunct in examining the forefoot biomechanics and bridge the gap between podiatric science and the proper design of foot orthotics. A prospective study for evaluating the relationship between the altered tissue properties and the development of forefoot problems can be done in the future, after measurement of the healthy forefoot mechanical properties.

Acknowledgements-The authors thank Dr. Hung-Tu Lin of the Guan Chin rehabilitation clinic, Taipei Hsien, Taiwan, for providing the illustration.

\section{REFERENCES}

Bennett MB, Ker RF. The mechanical properties of the human subcalcaneal fat pad in compression. J Anat 1990;171:131-138.
Bojsen-Møller F, Flagstad KE. Plantar aponeurosis and internal architecture of the ball of the foot. J Anat 1976;121:599-611.

Brink T. Induration of the diabetic foot pad: Another risk factor for recurrent neuropathic plantar ulcers. Biomed Tech 1995;40:205-209.

Cavanagh PR. Plantar soft tissue thickness during ground contact in walking. J Biomech 1999;32:623-628.

Dreeben S, Thomas PBM, Noble PC, Tullos HS. A new method for radiography of weight-bearing metatarsal heads. Clin Orthop 1987; 224:260-267.

Edelstein JE. Foot care for the aging. Phys Ther 1988;68:1882-1886.

Fung YC. Biomechanics: Mechanical properties of living tissues. 2nd ed. New York: Springer-Verlag, 1993.

Gefen A, Megido-Ravid M, Azariah M, Itzchak Y, Arcan M. Integration of plantar soft tissue stiffness measurements in routine MRI of the diabetic foot. Clin Biomech 2001;16:921-925.

Gooding GAW, Stess RM, Graf PM, et al. Sonography of the sole of the foot: Evidence for loss of foot pad thickness in diabetes and its relationship to ulceration of the foot. Invest Radiol 1986;21:45-48.

Haut TL, Haut RC. The state of tissue hydration determines the strain-rate-sensitive stiffness of human patellar tendon. J Biomech 1997;30:79-81.

Hsu TC, Wang CL, Shau YW, et al. Altered heel-pad mechanical properties in patients with type 2 diabetes mellitus. Diabet Med 2000;17:854-859.

Hsu TC, Wang CL, Tsai WC, Kuo JK, Tang FT. Comparison of the mechanical properties of the heel pad between young and elderly adults. Arch Phys Med Rehab 1998;79:1101-1104.

Kinoshita H, Francis PR, Murase T, Kawai S, Ogawa T. The mechanical properties of the heel pad in elderly adults. Eur J Appl Physiol 1996;43:404-409.

Klaesner JW, Hastings MK, Zou D, Lewis C, Mueller MJ. Plantar tissue stiffness in patients with diabetes mellitus and peripheral neuropathy. Arch Phys Med Rehab 2002;83:1796-1801.

Kuhns JG. Changes in elastic adipose tissue. J Bone Joint Surg 1949; 31-A:542-547.

Prichasuk S, Mulpruek P, Siriwongpairat P. The heel-pad compressibility. Clin Orthop Rel Res 1994;300:197-200.

Quirk R. Metatarsalgia. Aust Fam Physician 1996;25:867-869.

Rozema A, Ulbrecht JS, Pammer SE, Cavanagh PR. In-shoe plantar pressures during activities of daily living: Implications for therapeutic footwear design. Foot Ankle Int 1996;17:352-359.

Shau YW, Wang CL, Shieh JY, Hsu TC. Non-invasive assessment of the viscoelasticity of peripheral arteries. Ultrasound Med Biol 1999;25:1377-1388.

Wang CL, Hsu TC, Shau YW, Shieh JY, Hsu KH. Ultrasonographic measurement of the mechanical properties of the sole under the metatarsal heads. J Orthop Res 1999;17:709-713.

Whitney KA. Foot deformities, biomechanical and pathomechanical changes associated with aging including orthotic consideration, Part II. Clin Podiatr Med Surg 2003;20:511-526.

Zheng YP, Choi YKC, Wong K, Chan S, Mak AFT. Biomechanical assessment of plantar foot tissue in diabetic patients using an ultrasound indentation system. Ultrasound Med Biol 2000;26:451-456. 